\title{
Propriedades Mecânicas e Molhabilidade de Filmes de Zeínas Extraídas de Glúten de Milho
}

\author{
Lucimara A. Forato, Douglas de Britto, Juliana A. Scramin, Luiz A. Colnago, Odilio B. G. Assis \\ Embrapa Instrumentação - CNPDIA
}

\begin{abstract}
Resumo: Zeínas são proteínas de reserva do milho (prolaminas), que podem ser extraídas através de solubilização em meio alcoólico. Essas proteínas são altamente hidrofóbicas, com elevado grau de polimerização. Neste estudo, zeínas do tipo $\alpha$ (massa molecular entre 10 e $22 \mathrm{kDa}$ ) foram extraídas do glúten do milho e caracterizadas com respeito às suas principais bandas de absorção espectroscópica na região do infravermelho. Blendas de zeínas com ácido oléico (AO) como plastificante foram avaliadas em diversas proporções e filmes processados por casting sobre superfície apolar. Filmes de zeínas sem plastificante mostraram-se inviáveis para manipulação e medidas, mas a adição de 1 e $2 \%$ em massa de $\mathrm{AO}$ proporcionou um significativo aumento do módulo de elasticidade, segundo análise realizada por DMA. A presença de plastificante introduz também irregularidades superficiais e leva a uma perda das características hidrofóbicas dessas proteínas.
\end{abstract}

Palavras-chave: Zeínas, biopolímeros, proteínas do milho, propriedades mecânicas, filmes por casting.

\section{Mechanical and Wetting Properties of Zein Films Extracted From from Corn Gluten Meal}

\begin{abstract}
Zeins comprise a group of maize storage proteins (prolamines) that can be extracted via solubization in alcoholic media. Such proteins are highly hydrophobic with elevated degree of polymerization. In the present study, zein type $\alpha$ (molecular mass between 19 and $22 \mathrm{kDa}$ ) was extracted from corn gluten meal and characterized concerning the main spectroscopy absorption bands in the infrared region. Cast films were processed by blending zein and oleic acid (OA) as plasticizer. Films with no plasticizer were extremely brittle, and thus impossible to handle or used for mechanical analysis. The addition of 1 or $2 \%$ wt OA resulted in significant increase in the elongation length, according to DMA analysis. The presence of the plasticizer led to microscopic surface irregularities and to a reduction in the original hydrophobic characteristics.
\end{abstract}

Keywords: Zein, biopolymers, maize protein, mechanical properties, cast films.

\section{Introdução}

Por serem baratas, resistentes, versáteis e apresentarem alta flexibilidade, as embalagens de polímeros sintéticos como o PET, o poliestireno, o polietileno e demais olefinas têm sido utilizadas na indústria de alimentos por mais de 50 anos. A quase totalidade desses materiais é contudo, de descartabilidade rápida e já ocupam de $15 \%$ a $20 \%$ do volume do lixo urbano ${ }^{[1]}$, causando impactos ambientais de diferentes magnitudes e de difícil remediação. Embora haja ultimamente uma conscientização e motivações de ordem pública para a recuperação e o reaproveitamento de embalagens plásticas, sua reciclagem ainda é incipiente e não é superior a $15 \%$ do total descartado ${ }^{[2]}$.

Nos últimos anos o incentivo ao uso de materiais biodegradáveis e ambientalmente amigáveis, tais como plásticos de origem bacteriana como os da família dos polihidroxialcanoatos (PHA), os derivados de proteínas ou aqueles base em amido termoplástico e demais polissacarídeos têm crescido e tendem a substituir gradualmente e, em determinadas aplicações, os polímeros sintetizados a partir do petróleo.

Dentre os chamados polímeros naturais, um material de interesse para a confecção de filmes para emprego em embalagens para contato com alimentos são os derivados de zeínas. As zeínas, ou prolaminas, são proteínas de reserva compostas por vários polipeptídeos que representam mais de $50 \%$ da massa total das proteínas presentes no endosperma do milho (Zea mays). Essas proteínas têm baixa qualidade nutricional e são indicadas para usos em aplicações diversas que não alimentícias, principalmente em farmacêutica como material de encapsulamento de drogas ${ }^{[3]}$, na impermeabilização de papeis e embalagens cartonadas ${ }^{[4]} \mathrm{e}$ associadas a polímeros sintéticos para minimizações de contato e deteriorações em alimentos ${ }^{[5]}$. Além disso, essas proteínas apresentam alto grau de polimerização, superiores aos encontrados nas poliamidas e no poliéster ${ }^{[6]}$.

Zeínas são consideradas proteínas globulares e constituídas de frações classificadas de acordo com sua massa relativa (Mr) e solubilidade, como zeínas $\alpha, \gamma, \beta$ e $\delta$. As zeínas $\alpha$ são as mais abundantes constituindo aproximadamente $80 \%$ de todas as zeínas e correspondente as proteínas com $\mathrm{Mr}=19 \mathrm{kDa}(\mathrm{Z19})$ e $\mathrm{Mr}=22 \mathrm{kDa}(\mathrm{Z} 22)^{[7]}$.

Essas proteínas contêm 10 segmentos helicoidais sucessivos dispostos de forma antiparalela que são estabilizados por ligações de hidrogênio ${ }^{[8]}$. Por serem ricas em resíduos de aminoácidos apolares (leucina, prolina, alanina, glicina, valina e outros), as zeínas $\alpha$ são altamente hidrofóbicas, portanto insolúveis em água, mas solúveis em meios alcoólicos ${ }^{[9]}$. Por conseguinte filmes produzidos a partir da diluição de zeínas puras apresentam também caráter hidrofóbico, o que pode ser potencialmente interessantes para aplicações como revestimentos ou barreiras à umidade e ao vapor de água. De um modo geral, filmes à base de zeínas apresentam também uma boa barreira ao transporte de oxigênio, dióxido de carbono e demais compostos voláteis ${ }^{[10]}$.

Os filmes puros de zeínas são extremamente frágeis havendo a necessidade da adição de plastificantes para a melhoria das propriedades mecânicas. Os plastificantes comumente adicionados às zeínas são tipicamente os polióis como o glicerol, o poli(etilenoglicol) e o sorbitol. O uso de ácidos graxos

Autor para correspondência: Odilio Benedito Garrido Assis, Embrapa Instrumentação - CNPDIA, Rua XV de Novembro, 1453, CEP 13561-206, São Carlos, 
plastificantes, como é o caso do ácido oléicos, tem sido relatado na elaboração de películas aplicadas na área de alimentos ${ }^{[1-14]}$.

Logo, os objetivos deste trabalho foram extrair e caracterizar zeínas do tipo $\alpha$ do glúten do milho, assim como, emprega-las na produção de filmes pelo processo de casting. O glúten do milho é um subproduto da indústria de amido, de baixo valor nutritivo e econômico, sendo muitas vezes descartado ou empregado essencialmente na alimentação animal ${ }^{[15]}$. Diferentes relações de proteínas/ácido oleico, como plastificante foram avaliados e os filmes resultantes caracterizados quanto às suas propriedades mecânicas e molhabilidade.

\section{Experimental}

\section{Processo de extração das zeínas}

Diversas metodologias têm sido descritas para a extração química das proteínas do milho, seja diretamente de grãos macerados ou de seus derivados industrialmente processados ${ }^{[3]}$. A maioria desses processos tem por base o uso de soluções alcoólicas, de baixa polaridade, empregadas como solventes. Segundo determinações de Shukla et al. ${ }^{[16]}$, as maiores eficiências de extração de zeínas foram obtidas fazendo uso de etanol concentrado como solvente, considerando que a fração solúvel em álcool constitui na maior parte (80-90\%) das proteínas presentes no milho, e a restante fracamente solúvel em álcali ${ }^{[17]}$. Adotamos neste trabalho a sequencia de extração desenvolvida por Forato ${ }^{[18]}$ a partir do glúten de milho, processo esse em corrente uso na unidade da Embrapa Instrumentação.

O glúten de milho (GM) foi fornecido pela Brasil Corn Products (Mogi das Cruzes, SP). O GM é um subproduto da produção de amido, de baixo custo e baixo valor nutricional e normalmente empregado como ração animal. Este glúten contém de $60 \%$ a $70 \%$ de sua massa constituída de zeínas, demais proteínas, óleo residual e alguns polissacarídeos remanescentes.

Para a extração das proteínas, o GM foi inicialmente tratado com hexano em extrator soxlhet por 24 horas para a remoção de gorduras. A seguir a massa restante foi agitada em solução de cloreto de sódio a 0,5 mol. $\mathrm{L}^{-1}$ por 6 horas (para remoção das albuminas, glutelina e globulinas). As zeínas foram obtidas através da mistura com etanol a $70 \%$ (por 24 horas) e precipitadas em rotaevaporador seguido por liofilização. Detalhes instrumentais e operacionais dessa extração podem ser encontrados em Forato ${ }^{[18]}$ e Forato et al. ${ }^{[19]}$.

\section{Caracterização das zeínas}

As proteínas liofilizadas resultantes foram caracterizadas pelas absorbâncias na região do infravermelho por espectroscopia com transformada de Fourier (FT-IR) em espectrômetro Perkin Elmer - Paragon 1000. Os espectros foram obtidos com 16 varreduras, resolução de $4 \mathrm{~cm}^{-1}$ na região de 4000 a $400 \mathrm{~cm}^{-1}$, preparadas sob forma de pastilhas de $\mathrm{KBr}$ (1 mg da proteína e $100 \mathrm{mg}$ de $\mathrm{KBr})$. As frações constituídas por zeínas- $\alpha$ foram caracterizadas por eletroforese em gel de poliacrilamida-dodecil sulfato de sódio (SDS/PAGE), seguindo procedimento padrão ${ }^{[20]}$. Utilizou-se sistema Bio-Rad mini sub Cell (Bio-Rad, Hercules, CA, USA), as medidas foram conduzidas em quadruplicatas (cuba vertical com quatro poços) para confirmação dos valores de massa molecular.

\section{Processamento dos filmes}

Para a preparação das soluções filmogênicas, as proteínas foram solubilizadas em etanol 70\% (30\% água) nas concentrações de 1,0; 2,0; 3,0; 4,0 e 5,0\% em massa. Ácido oléico (Synth, Diadema, SP), empregado como plastificante foi separadamente adicionado em cada concentração na proporção de 0,$25 ; 0,50 ; 1,00$ e 2,00\% em massa e homogeneizado por agitação moderada na temperatura ambiente.

Os filmes foram obtidos por casting sobre superfície apolar de acrílico. Após evaporação espontânea do solvente na temperatura ambiente $\left(25 \pm 3{ }^{\circ} \mathrm{C}\right)$, os filmes foram manualmente destacados. As espessuras foram medidas empregando um micrometro (Scherr-Tumico Inc.). Cinco medias foram tomadas em posições aleatórias ao longo do comprimento de cada amostra. Aspectos superficiais dos filmes nas diversas formulações foram observados por microscopia eletrônica de varredura (MEV) em um microscópio Jeol JSM-6510LV, em amostras previamente metalizadas com ouro (Balzers Union Sputtering).

\section{Propriedades mecânicas e de molhabilidade}

As propriedades mecânicas foram analisadas em amostras cortadas nas dimensões $15,0 \times 6,0 \times 0,15 \mathrm{~mm}$ em sistema DMA (Dynamic Mechanical Analysis). O equipamento utilizado foi um equipamento da TA Instruments modelo DMA 2930 nas seguintes condições: Modo tensão, frequência de $1 \mathrm{~Hz}$, amplitude de $20 \mathrm{~mm}$. Diferenças entre médias para cada condição foram comparadas utilizando o teste de Tukey ao nível de 5\% de significância.

As medidas de ângulo de contato foram realizadas em sistema CAN101 Optical Contact Angle Meter (KSV Instruments). Seis gotas de água deionizada $(5 \mu \mathrm{L})$ foram consideradas em cada superfície. Os ângulos foram registrados por sistema óptico imediatamente após a disposição das gotas, sendo todas as medidas determinadas digitalmente. Todos os ensaios foram realizados ao ar e em temperatura ambiente.

\section{Resultados e Discussão}

$\mathrm{Na}$ identificação das estruturas secundárias (ES) de proteínas por FTIR utiliza-se geralmente a banda da amida I como referência considerando que a posição dessa absorção depende do tipo de ES predominante. Temos assim no espectro das zeínas obtidas a partir do glúten, apresentado na Figura 1, a amida I entre as regiões de 1700 e $1600 \mathrm{~cm}^{-1}$, correspondente ao estiramento da ligação $\mathrm{C}=\mathrm{O}$ dos grupos peptídicos em conjunto com contribuições do estiramento $\mathrm{CN}$ e deformações no plano $\mathrm{CCH}^{[20]}$. A amida II caracteriza-se por vibração entre 1550 e $1500 \mathrm{~cm}^{-1}$ e é considerada como uma combinação do estiramento do $\mathrm{CN}$ e deformações no plano $\mathrm{NH}$ dos grupos peptídicos.

De um modo geral as bandas de amina das proteínas são convoluções e sobreposições de diversas bandas componentes de diferentes ES de proteínas como as hélices- $\alpha$, folhas- $\beta$ e configurações não ordenadas de fragmentos de polipetídeos ${ }^{[22]}$. Geralmente assumem-se que os principais componentes da amida I sejam segmentos hélices- $\alpha^{[21,23]}$ e que na amida II predominem também as hélices- $\alpha$, embora com frações significativas de estruturas folhas- $\beta^{[21,22,24]}$.

A amida III, com banda próxima a $1250 \mathrm{~cm}^{-1}$ é característica de grupos peptídicos e geralmente se decompõe em uma série de ES entre a região de 1200 e $1350 \mathrm{~cm}^{-1}$ correspondentes a diversas conformações $^{[24]}$.

Como pôde ser observado pela comparação de ambos espectros (glúten e zeínas), as principais estruturas são preservadas no processo de extração das proteínas, embora identifique-se remoções de porções de amido (região de 1150 a $1020 \mathrm{~cm}^{-1}$ ) e de lipídeos (2925 a $2845 \mathrm{~cm}^{-1}$ e $1745 \mathrm{~cm}^{-1}$ ) evidenciadas na Figura 1. Um resumo suscinto das regiões de interpretação de espectro de FTIR de proteínas está disposto na Tabela 1, com base nas classificações apresentadas por Naumann ${ }^{[25]}$. 
Análises complementares por eletroforese (SDS/PAGE) da fração solúvel em álcool revelaram bandas polimórficas em função das massas moleculares identificadas pelas variações em intensidade. Para o composto extraído há bandas em baixas concentrações em 14KDa e entre 27-66 KDa demonstrando uma grande variabilidade nas mobilidades para diferentes massas (primeira coluna). As frações predominantes contudo, são observadas para bandas variando em 19-22KDa e em 22-26KDa. Essas proteínas são denominadas Z19 e Z22 respectivamente e são constituídas por 210 a 245 amino ácidos apresentando diferenças estruturais e conformacionais ${ }^{[26]}$. O perfil eletroforético dessas frações foi detalhado e podem ser visualizadas em Scramin et al. ${ }^{[14]}$.

As proteínas relacionadas a essas bandas têm domínios não repetitivos nos terminais carboxi e amino e repetições homólogas na região central. A Z19 tem 9 blocos de repetições homólogas de 20 aminoácios e a Z22 tem 10 blocos $^{[27]}$ e correspondem à polimorfismos das zeínas- $\alpha$. O SDS/PAGE do total de proteínas indica que a extração das zeínas se deu de forma satisfatória com a presença de pequena fração de não-zeínas (albumina, globulina e glutelina). O método aqui empregado apresentou uma eficiência de extração de zeínas do glúten com rendimento em torno de 3 a 5\%.

Os filmes processados a partir desse material com combinações de ácido oleico, destacaram-se espontaneamente do acrílico após a completa evaporação do solvente, apresentaram coloração amarelada, transparência e brilho irregular. A coloração amarela predominante no filme curado deve-se a presença de carotenoides na proteína, predominentemente $\beta$-caroteno, zeaxantina e luteína em maior quantidade ${ }^{[28]}$. Em aplicações comerciais as zeínas podem ser descoloridas para a geração de membranas incolores ${ }^{[28]}$. Os filmes destacados apresentam espessuras médias em torno de $150 \pm 17 \mu \mathrm{m}$. A Figura 2 ilustra o aspecto de um filme com 2,0\% de AO, na sua forma líquida (gel) e após a evaporação do solvente (cura).

Entre as combinações zeínas-plastificantes ensaiadas, apenas uma mostrou-se viável à confecção de filmes com plasticidade mínima aceitável para alguma aplicação como embalagem. As concentrações de 1,0; 2,0 e 3,0\% em massa de zeínas resultaram em películas extremamente frágeis, independentes da adição de plastificante. Esses filmes fragmentavam-se durante o manuseio inviabilizando qualquer

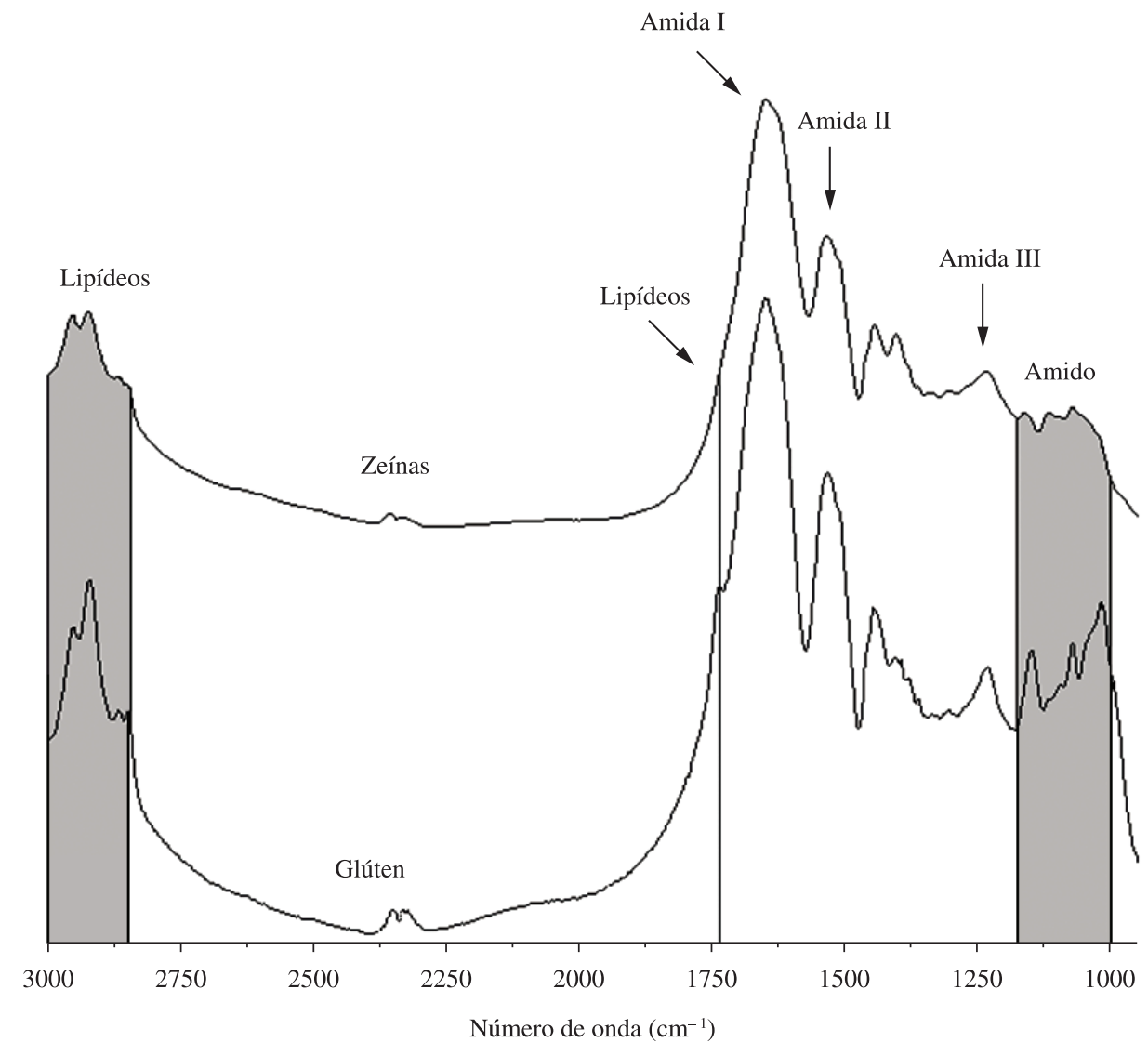

Figura 1. Espectro de FTIR do glúten e das zeínas de milho com identificação das principais bandas de absorbância e regiões de amido e lipídios em destaque.

Tabela 1. Principais regiões de absorções em espectros de FTIR em proteínas, com base em Naumann ${ }^{[25]}$.

\begin{tabular}{|c|c|}
\hline Região espectral $\left(\mathrm{cm}^{-1}\right)$ & Descrição \\
\hline 3100 a 2800 & Vibrações de estiramento $\mathrm{C}-\mathrm{H}$ de grupos funcionais $\mathrm{CH}_{3} \mathrm{e}=\mathrm{CH}_{2}$, geralmente de ácidos graxos e cadeia lateral de alguns aminoácidos. \\
\hline 1800 a 1500 & $\begin{array}{l}\text { Bandas de amida I e II, que são as bandas mais intensas. Permitem quantificar a predominância de estruturas secundárias } \alpha \text { ou } \beta \\
\text { de proteínas. Bandas em aproximadamente } 1740 \mathrm{~cm}^{-1} \text { são de vibrações de estiramento } \mathrm{C}=\mathrm{O} \text { do grupo funcional éster em lipídios. }\end{array}$ \\
\hline 1300 a 1500 & $\begin{array}{l}\text { Predominantemente }=\mathrm{CH}_{2} \mathrm{e}-\mathrm{CH} \text { de lipídios e proteínas. Banda pouco intensa próxima a } 1400 \mathrm{~cm}^{-1} \text { é atribuída à vibrações de } \\
\text { estiramento simétrico do grupo }-\mathrm{COO}^{-} \text {da cadeia lateral de aminoácidos e ácidos graxos. }\end{array}$ \\
\hline 1200 a 1000 & $\begin{array}{l}\text { Sequência complexa de picos devidos principalmente as vibrações de estiramento C-O-C e C-O-P de vários oligo - e } \\
\text { polissacarídeos (amidos). }\end{array}$ \\
\hline
\end{tabular}


análise subsequente. Por sua vez, para a maior concentração avaliada, de 5,0\% (w/w) (42,6 g.L $\left.\mathrm{L}^{-1}\right)$, não ocorre uma total solubilização das proteínas adicionadas, não gerando uma solução homogênea e por conseguinte os filmes formados são altamente irregulares, seja na espessura ou na distribuição da fração proteica.

As medidas mecânicas foram então realizadas para os filmes processados com 4,0\% em massa de zeínas $\left(34,0\right.$ g.L $\left.\mathrm{L}^{-1}\right)$, para adições de plastificantes variáveis de 0,$25 ; 0,50 ; 1,00$ e $2,00 \%$ de ácido oléico.

As analises por DMA, indicam diferenças para as pequenas alterações nas concentrações de plastificante, conforme curvas de ensaio de tração dispostas na Figura 3. O limite de resistência à tração na ruptura $\left(\sigma_{\mathrm{R}}\right)$, embora permaneçam em um intervalo bem próximo de valores, segue uma relação linear com o teor de plastificante adicionado, melhor visualizada na forma gráfica (Figura 4), com boa relação de coeficiente quadrático $\mathrm{R}^{2}=0,97$. De um modo geral os filmes apresentam fratura frágil com pequena elongação, não superior a $2 \%$. Os resultados numéricos estão dispostos na Tabela 2.

A propriedade mecânica que apresentou maior variação foi $o$ Módulo de Elasticidade, indicando o efeito plastificante do AO, resultando em um aumento no alongamento percentual.

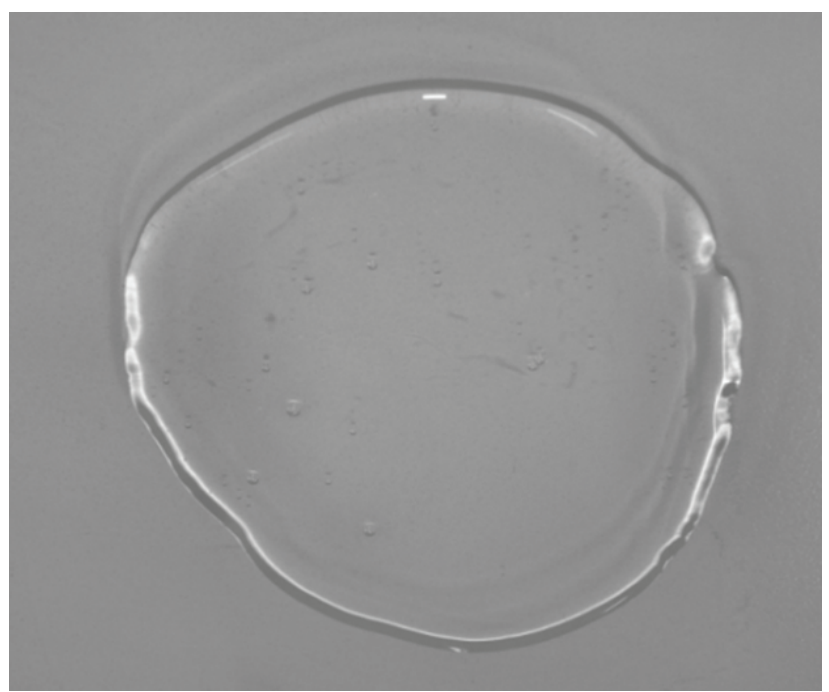

(a)
Na literatura encontramos descritos processamentos de filmes a partir de zeínas em diversas concentrações de proteínas, embora a maioria esteja acima da solubilidade o que resulta em filmes não homogêneos com clara separação de fases e propriedades mecânicas irregulares ${ }^{[6]}$. Encontram-se, por exemplo, descrições de filmes processados com $100^{[29]}, 136^{[30]}$ e $160^{[6]}$ g..$^{-1}$, concentrações essas acima do limite de solubilidade das zeínas ${ }^{[31]}$. Dados referentes a soluções, nas quais filmes com estruturas homogêneas são conseguidas, indicam concentrações entre 10 a 34 g.L. - $^{-1}$ para os quais propriedades mecânicas semelhantes as aqui apresentadas são registradas $^{[32,33]}$.

De forma similar, adições maiores que 2,0\% de AO como plastificante não tem levado a melhoras significativas nas propriedades mecânicas de filmes de zeínas ${ }^{[34]}$. Avaliações de altas concentrações de plastificantes indicam que estes também contribuem para a formação de estruturas heterogêneas com separação de fases entre as proteínas e o plastificante ${ }^{[13,30]}$.

Com respeito ao aspecto topográfico dos filmes, vemos nas fotomicrografias da Figura 5, duas imagens representativas do filme sem plastificante (Figura 5a), onde predominam trincas frágeis ao longo de toda a matriz e, como já comentado, inviabiliza qualquer

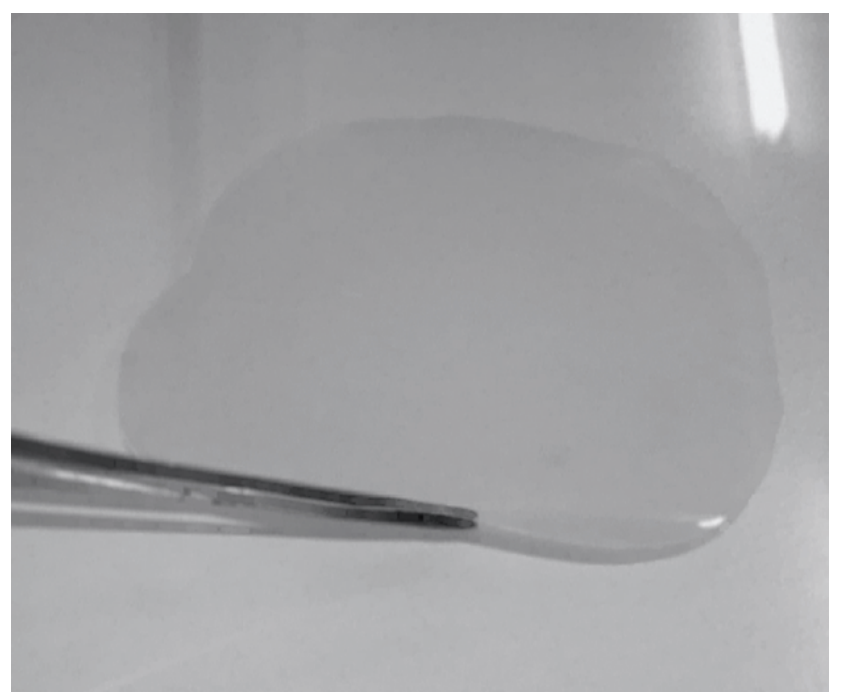

(b)

Figura 2. Imagens do (a) gel depositado e do filme formado (b) após a evaporação do solvente sobre superfície apolar (casting). Embora as imagens em tons de cinza não permitam perceber, tanto o gel como o filme apresentam coloração tirantes ao amarelo, sendo a superfície do filme ligeiramente fosca.

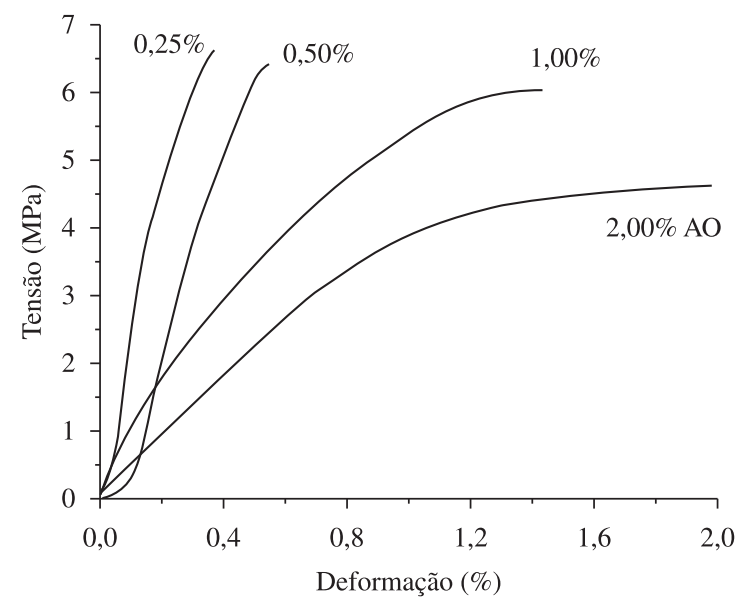

Figura 3. Curvas tensão X deformação para filmes processados com $4,0 \%$ de zeínas (w/w) e adições variadas de AO como plastificante.

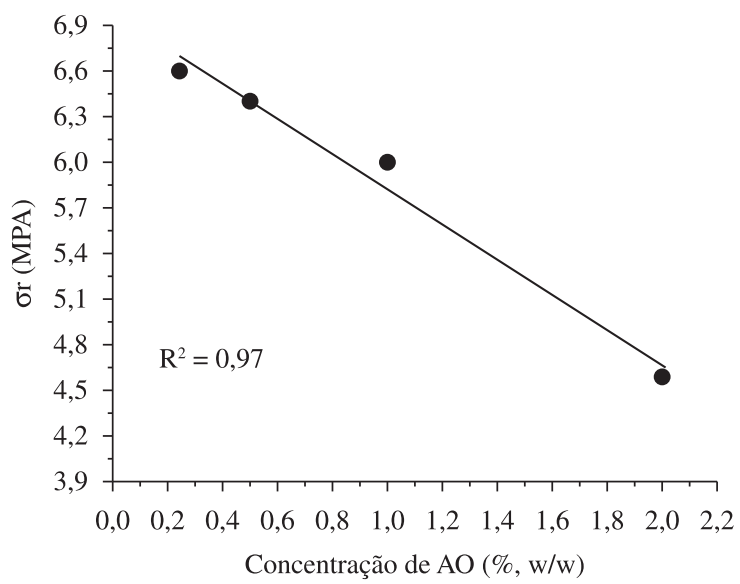

Figura 4. Relação entre limite de resistência à tração na ruptura $\left(\sigma_{R}\right)$ e concentração de plastificante. 
Tabela 2. Propriedades mecânicas de filmes de zeínas a 4,0\% em massa em função da concentração de plastificante (AO)*.

\begin{tabular}{cccc}
\hline Concentração de plastificante (\%) & Resistência à tração (MPa) & Módulo de Elasticidade (MPa) & Alongamento percentual (\%) \\
\hline 0,25 & $6,6 \pm 2,0^{\mathrm{a}}$ & $2309 \pm 100^{\mathrm{c}}$ & $0,4 \pm 0,1^{\mathrm{g}}$ \\
0,50 & $6,4 \pm 2,0^{\mathrm{a}}$ & $1587 \pm 80^{\mathrm{d}}$ & $0,5 \pm 0,1^{\mathrm{g}}$ \\
1,00 & $6,0 \pm 1,3^{\mathrm{a}}$ & $418 \pm 50^{\mathrm{e}}$ & $1,5 \pm 0,1^{\mathrm{h}}$ \\
2,00 & $4,6 \pm 0,7^{\mathrm{b}}$ & $302 \pm 25^{\mathrm{f}}$ & $2,1 \pm 0,1^{\mathrm{h}}$ \\
\hline
\end{tabular}

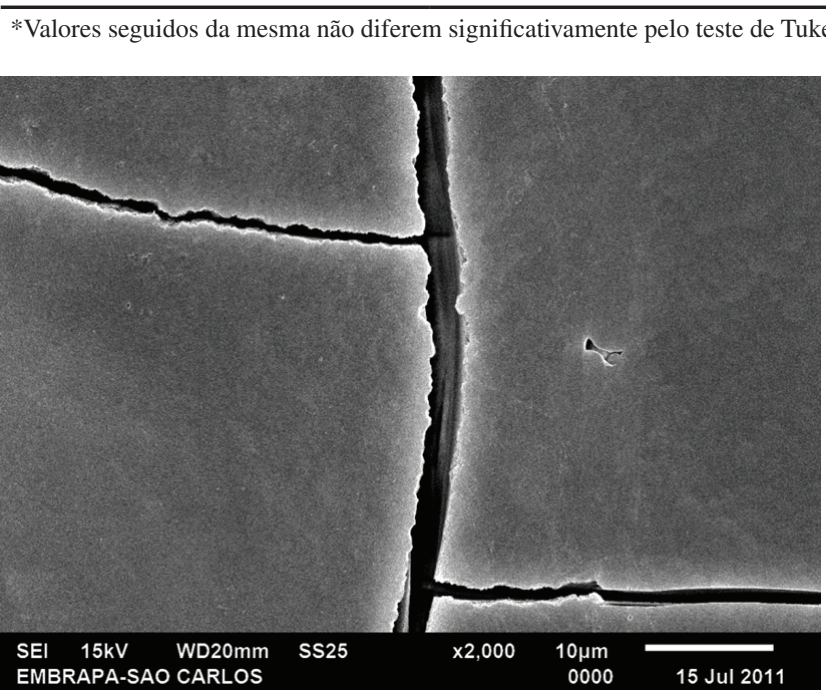

(a)

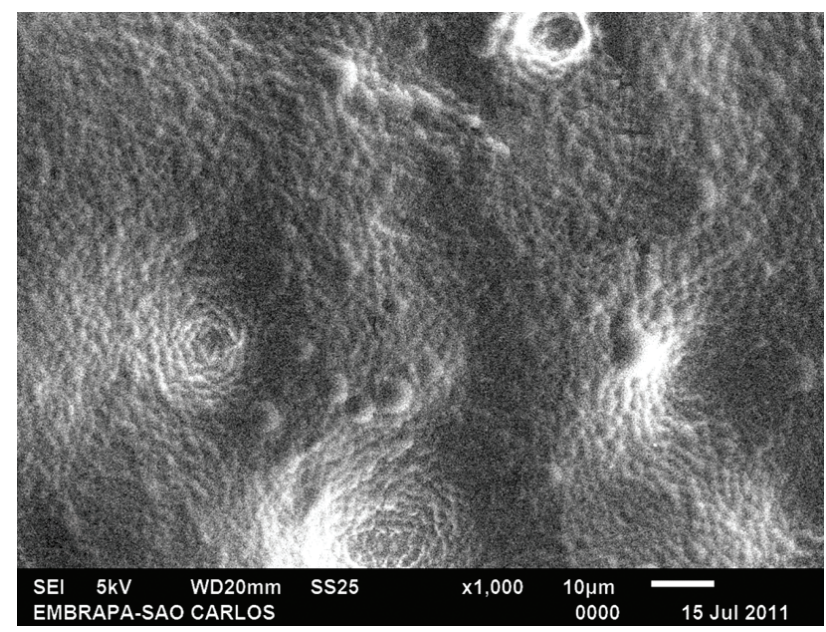

(b)

Figura 5. Fotomicrografias MEV típicas de filmes de zeínas (4\% em massa) obtidos por casting: a) Filme sem plastificante; b) filme com $1 \%$ wt de ácido oleico como plastificante.

tipo de emprego e mesmo o manuseio e um filme de mesma concentração com a adição de $1 \%$ de plastificante (Figura 5 b) onde observa-se a formação de irregularidades topográficas em escala microscópica, porém com ausência de trincas. Essas estruturas são muito similares as publicadas por Lai \& Padua ${ }^{[6]}$, também avaliando o AO, nas quais irregularidades e separações de fases foram observadas com o aumento do teor de plastificante. Uma análise mais detalhada das características superficiais das formulações aqui apresentadas, com análises de rugosidade e aderência por medida em microscopia de força atômica, foi recentemente publicada ${ }^{[14]}$.

A adição de plastificante influenciou a molhabilidade dos filmes, estimada pela determinação dos ângulos de contato das amostras com a água e a medida que se aumentou o teor de plastificante, observou-se um decréscimo do ângulo de contato medido, e consequentemente, um aumento da molhabilidade dos filmes (Figura 6). Há dois aspectos a serem abordados nestes resultados. $\mathrm{O}$ primeiro refere-se à ação do plastificante em uma matriz polimérica, que pode ser entendida como moléculas que se ligam às cadeias principais enfraquecendo predominantemente as ligações de hidrogênio que conferem estabilidade entre as cadeias. Essas interações com as moléculas de plastificante reduzem as forças intermoleculares facilitando o deslocamento relativo das cadeias ${ }^{[35]}$. Com o aumento da concentração de plastificante o espaço entre as cadeias aumenta, nestas condições a difusão é facilitada ${ }^{[36,37]}$, elevando a penetração de moléculas de água para o interior do filme. Com respeito ao ácido oleico (AO) como plastificante, Wang $\&$ Padua $^{[38]}$ registram que a permeação de água, principalmente na forma de vapor, é facilitada com um aumento do teor de plastificante em filmes de zeínas.

Em estudo realizado por Forato et al. ${ }^{[39]}$ em medidas por $\mathrm{RMN}{ }^{13} \mathrm{C}$ no estado sólido, ficou evidente que as interações entre moléculas de $\mathrm{AO}$ e as zeínas se dão preferencialmente entre os grupos carboxílicos $(-\mathrm{COOH})$ presentes no AO e os resíduos de argininas presentes na estrutura das zeínas.
As argininas são aminoácidos polares que possuem um agrupamento guanidínico lateral que podem ser ionizado. No processo de ionização o grupamento guanidinico perde um próton quando seu grupo carboxila se ioniza, podendo assim formar ligações iônicas com grupos carboxílicos (Figura 7). As argininas contudo, estão presentes em pequeno número na estrutura das zeínas, na razão de duas ou três para cada sequência ${ }^{[38]}$. Com o aumento da concentração de plastificante haverá proporcionalmente poucos resíduos de arginina para interação, fazendo com que os grupos carboxílicos do $\mathrm{AO}$ que não reagiram permaneceram disponíveis para se ligarem com as moléculas de água. A este fator soma-se que as cadeias de hidrocarbonetos apresentam forte atração entre si principalmente através dos terminais hidrofóbicos, formando configurações como micelas macromoleculares. Neste caso a hidratação é facilitada considerando que este tipo de organização conduz a orientação dos componentes polares em direção à superfície ${ }^{[40]}$. Análises cristalográficas confirmam a formação de bicamadas $^{[32]}$ ou entrelaçadas de $\mathrm{AO}$ quando elevadas concentrações são adicionados às zeínas ${ }^{[34]}$.

Outro aspecto observado e registrado em publicação prévia ${ }^{[14]}$, é que após os primeiros segundos de contato da gota com a superfície, há um comportamento de recuo do ângulo medido com tendência a estabilização após aproximadamente alguns minutos. Este comportamento, denominado receding (ou ângulo de recuo), ocorre em todos os filmes independentes do teor de plastificante e é um aspecto comum na maioria das superfícies biopolímericas ${ }^{[41]}$.

O comportamento de recuo pode ser interpretado como um indicativo da capacidade de sorção de água pelo material seja por infiltração capilar ou ainda considerada como um reflexo da reorientação de grupos hidrofílicos em direção à superfície em função da hidratação gerada pela interação com a água ${ }^{[42]}$. De acordo com modelo proposto por Watt \& D'Arcy ${ }^{[43]}$, para estudos em proteínas, nos locais de hidratação ocorrem alterações nas estruturas secundárias nas quais tanto os grupos polares como os 


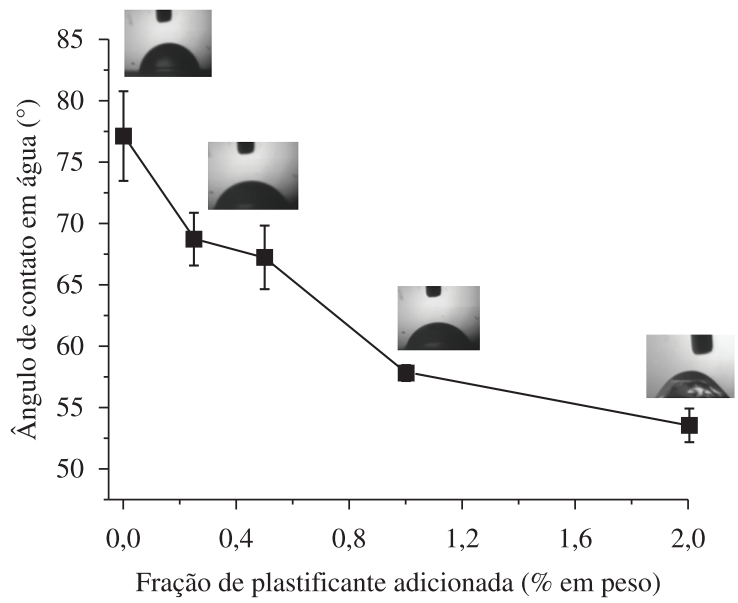

Figura 6. Variação estática do ângulo de contato sobre filmes de zeínas para diferentes concentrações de plastificante $(\mathrm{AO})$ e aparência típica das gotas sobre a superfície.

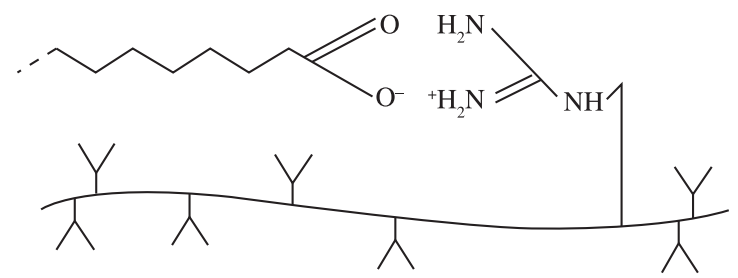

Figura 7. Prováveis sítios de interação entre as zeínas e o ácido oleico, nos quais os resíduos de arginina carregados interagem com o ácido ionizado.

grupos peptídicos ligados à matriz polimérica se reorientam de forma a prover sítios específicos para associações com moléculas de água. Essa reorientação tem sido modelada como um mecanismo que ocorre para minimizar a energia livre interfacial e, portanto, estabelecer uma maior estabilidade no sistema ${ }^{[44,45]}$, o que parece ser facilitado com o aumento do teor de plastificante.

Segundo Yoshino et al. ${ }^{[46]}$, o etanol empregado como solvente das proteínas também tem sua contribuição na formação de superfícies menos hidrofóbicas, principalmente quando os filmes são processados por casting. As moléculas de etanol, assim como as zeínas, apresentam caráter anfifílico, ou seja, com grupos funcionais hidrofílicos e hidrofóbicos. Quando em solução predominam as associações entre as partes hidrofóbicas (das proteínas e do álcool) embora a afinidade nos grupos hidrofílicos por água seja consideravelmente mais acentuada ${ }^{[38]}$.

Assim, no processo de evaporação do solvente, as regiões hidrofílicas, que estão mais fortemente ligadas à água, serão as ultimas a se orientarem na interface filme-ar para evaporação expondo assim seus grupos polares à superfície com tendência a permanecer desta forma após a cura do filme. Avaliações realizadas na superfície exposta ao ar e na superfície basal indicam variações perceptíveis na hidrofobicidade e na permeação de vapor de água entre as faces ${ }^{[46]}$. Este é um aspecto importante a ser considerado na definição de aplicações, principalmente na área de alimentos, para definir qual face do filme entrará em contato com os produtos.

\section{Conclusão}

O método adotado para a extração de zeínas mostrou-se eficiente embora com baixa recuperação média de zeínas $\alpha$. A massa recuperada representa entre 3 a 5\% do total das proteínas presentes no glúten. Filmes a partir dessas proteínas podem ser obtidos facilmente por evaporação espontânea do solvente sobre superfície apolar (técnica de casting) na temperatura ambiente. Filmes sem plastificante mostraram-se frágeis e inviáveis ao manuseio. Pequenas adições de ácido oleico (AO), como plastificante mostrou-se benéfica na formação de filmes com maior alongamento percentual. Filmes processados na relação de $4,0 \%$ de zeínas e $1,0 \%$ de AO (porcentagens em massa) apresentaram as melhores propriedades mecânicas. A adição de plastificante, contudo, introduz alterações significativas nas características de hidrofilicidade com redução do ângulo de molhabilidade em torno de $20^{\circ}$ para uma adição de apenas $1 \%$ de $\mathrm{AO}$.

\section{Agradecimentos}

Os autores agradecem ao CNPq e à FAPESP por auxílios recebidos. Este trabalho é parte das pesquisas em andamento financiadas pela Rede AgroNano da Embrapa.

\section{Referências Bibliográficas}

1. Santa-Maria, L. C.; Leite, M. C. A. M.; Aguiar, M. R. M. P., Oliveira, R. O.; Arcanjo, M. E. \& Carvalho, E. L. - Quim. Nova Esc., 17, p.32 (2003).

2. Ambiente Brasil - "Reciclagem de Plástico: Classificação dos plásticos, tipos de reciclagem". Disponível em: <http://ambientes. ambientebrasil.com.br/residuos/reciclagem/reciclagem _de_plastico. html>. Acesso em: 22 set. 2011.

3. Lawton, J.W. - Cereal Chem., 79, p.1 (2002). http://dx.doi.org/10.1094/ CCHEM.2002.79.1.1

4. Trezza, T. A. \& Vergano, P. J. - J. Food Sci., 59, p.912 (1994). http:// dx.doi.org/10.1111/j.1365-2621.1994.tb08156.x

5. Lee, J.-W.; Son, S.-M. \& Hong, S.-I. - J. Food Eng., 86, p.484 (2008). http://dx.doi.org/10.1016/j.jfoodeng.2007.10.025

6. Lai, H.-M. \& Padua, G. W. - Cereal Chem., 74, p.771 (1997). http:// dx.doi.org/10.1094/CCHEM.1997.74.6.771

7. Bicudo, R. C.; Bicudo, T. C.; Forato, L. A.; Colnago, L. A. \& Lanças, F. M. - "Análise de zeínas $\alpha$ do milho por LC-ESI-Q/TOF", Comunicado Técnico n.77, Embrapa Instrumentação, CNPDIA, São Carlos, 3p. (2006).

8. Matsushima, N.; Danno, G. I.; Takezawa, H. \& Izumi, Y. - Biochim. Biophys. Acta, 1339, p.14 (1997). http://dx.doi.org/10.1016/S01674838(96)00212-9

9. Forato, L. A.; Yushmanov, V. E. \& Colnago, L. A. - Biochemistry, 43, p.7121 (2004). http://dx.doi.org/10.1021/bi035562k

10. Hernandez-Muñoz, P.; Villalobos, R. \& Chiralt, A. - Food Hydrocoll., 18, p.403 (2004).

11. Fernández, L.; Apodaca, E. D.; Cebrián, M.; Villarán, M. C. \& Maté, J. I. - Eur. Food Res. Technol., 224, p.415 (2007). http://dx.doi. org/10.1007/s00217-006-0305-1

12. Rakotonirainy, A. M.; Wang, Q. \& Padua, G. W. - J. Food Sci., 66, p.1108 (2001). http://dx.doi.org/10.1111/j.1365-2621.2001.tb16089.x

13. Almeida, C. B.; Catelam, K. T.; Cornélio, M. L. \& Lopes Filho, J. F. - Food Technol. Biotech., 48, p.19 (2010).

14. Scramin, J. A.; Britto, D.; Forato, L. A., Bernardes-Filho, R.; Colnago, L. A. \& Assis, O. B. G. - Int. J. Food Sci. Tech. 46, p.2145 (2011). http://dx.doi.org/10.1111/j.1365-2621.2011.02729.x

15. Cargill. - "Nutrição Animal”. Disponível em: <http://www.cargill.com. $\mathrm{br} / \mathrm{brazil} / \mathrm{pt} / \mathrm{produtos}$-servicos/nutricao-animal/index.jsp $>$. Acesso em: 18 nov. 2011.

16. Shukla, R.; Cheryan, M. \& De Vor, R. E. - Cereal Chem., 77, p.724 (2000). http://dx.doi.org/10.1094/CCHEM.2000.77.6.724

17. Kampen, W. H. "Recovery of protein isolate and/or starch from cereal grains", United States Patent 5.410.021 (1995). 
18. Forato, L. A. - "Estudos das Estruturas das Zeínas por RMN, FTIR e MFA", Tese de Doutorado, Universidade de São Paulo, Brasil (2000).

19. Forato, L. A.; Bicudo, T. C. \& Colnago, L. A. - Biopolymers, 72, p.421 (2003). http://dx.doi.org/10.1002/bip.10481

20. Laemmli, U. K. - Nature, 227, p. 680 (1970). http://dx.doi org/10.1038/227680a0

21. Duodu, K. G.; Tang, H.; Grant, A.; Wellner, N.; Belton, P. S. \& Taylor, J. R. N. - J. Cereal Sci., 33, p.261 (2001). http://dx.doi.org/10.1006/ jcrs. 2000.0352

22. Surewicz, W. K. \& Mantsch, H. H. - Biochim. Biophys. Acta, 952 , p.115 (1988). http://dx.doi.org/10.1016/0167-4838(88)90107-0

23. Bandekar, J. Biochim. Biophys. Acta, 1120, p.123(1992). http://dx.doi. org/10.1016/0167-4838(92)90261-B

24. Subramanian, S. \& Sampath, S. - Biomacromolecules, 8, p. 2120 (2007). http://dx.doi.org/10.1021/bm0701999

25. Naumann, D. "Infrared spectroscopy in microbiology", In: Encyclopedia of Analytical Chemistry. Meyers, R.A. (Ed.), John Wiley \& Sons Ltd, Chichester, U.K., p.102 (2000).

26. Tatham, A. S.; Field, J. M.; Morris, V. J.; I'Anson, K.J.; Cardle, L.; Dufton, M. J. \& Shewry, P. R. - J. Biol. Chem., 268, p.26253 (1993).

27. Bicudo, T. C.; Forato, L. A.; Batista, L. A. R. \& Colnago, L. A. - Anal. Bioanal. Chem., 383, p.291 (2005). http://dx.doi.org/10.1007/s00216005-0003-Z

28. Sessa, D. J.; Eller, F.J.; Palmquist, D. E. \& Lawton, J. W. - Ind. Crop. Prod., 18, p.55 (2003). http://dx.doi.org/10.1016/S09266690(03)00033-5

29. Yoshino T.; Isobe S. \& Maekawa T. - JAOCS, 79, p.345 (2002). http:// dx.doi.org/10.1007/s11746-002-0486-6

30. Emmambux, M. N. \& Stading, M. - Food Hydrocoll., 21, p.1245 (2007).

31. Zhong, Q. \& Jin, M. - Food Hydrocoll., 23, p.2380 (2009). http:// dx.doi.org/10.1016/j.foodhyd.2009.06.015

32. Wang Q.; Crofts, A. R. \& Padua, G. W. - J. Agric. Food Chem., 51, p.7439 (2003). http://dx.doi.org/10.1021/jf0340658

33. Parris, N. \& Dickey, L. C. - J. Agric. Food Chem., 49, p.3757 (2001). http://dx.doi.org/10.1021/jf0011790
34. Lai, H.-M.; Geil, P. H. \& Padua, G. W. - J. Appl. Polym. Sci., 71, p.1267 (1999). http://dx.doi.org/10.1002/(SICI)10974628(19990222)71:8\%3C1267::AID-APP7\%3E3.0.CO;2-O

35. Shaw, N. B.; Monahan, F. J.; O'Riordan, E. D. \& O'Sullvan, M. - J. Food Sci., 67, p.164 (2002). http://dx.doi.org/10.1111/j.1365-2621.2002. tb11377.x

36. Banker, G. S. - J. Pharm. Sci., 55, p.81 (1966). http://dx.doi. org/10.1002/jps.2600550118

37. Paramawati, R.; Yoshino, T. \& Isobe, S. - Food Sci. Technol. Res., 7, p.191 (2001). http://dx.doi.org/10.3136/fstr.7.191

38. Wang, Q.; Geil, P. \& Padua, G. - J. Polymer Environ., 12, p. 197 (2004). http://dx.doi.org/10.1023/B:JOOE.0000038552.88467.fc

39. Forato, L.A.; Doriguetto, A.C.; Fischer, H.; Mascarenhas, Y.P.; Craievich, A.F. \& Colnago, L.A. - J. Agric. Food Chem., 52, p.2382 (2004). http:// dx.doi.org/10.1021/jf035020+

40. Dhathathreyan, A. \& Maheshwari, R. - Langmuir, 18, p.10039 (2002). http://dx.doi.org/10.1021/la026069x

41. Xinping, W.; Zhifang, C. \& Zhiquan, S. - Science in China Ser. B Chem., 48, p.553 (2005).

42. Gugliuzza, A. \& Drioli, E. - Eur. Polym. J., 40, p.2381 (2004). http:// dx.doi.org/10.1016/j.eurpolymj.2004.06.005

43. Watt, I. C. \& D'Arcy, R. L. - J. Polym. Sci.: Polym. Symp., 55, p.155 (1976). http://dx.doi.org/10.1002/polc.5070550117

44. Carey, D. H.; Grunzinger, S. J. \& Ferguson, G. S. - Macromolecules, 33, p.8802 (2000). http://dx.doi.org/10.1021/ma000189z

45. Fonseca, L. C.; Corrêa, N. C. R.; Garrote-Filho, M. S.; Cunha, C. C. \& Penha-Silva, N. - Quim. Nova, 29, p.543 (2006). http://dx.doi org/10.1590/S0100-40422006000300024

46. Yoshino, T.; Isobe, S. \& Maekawa, T. - JAOCS, 79, p.345 (2002). http://dx.doi.org/10.1007/s11746-002-0486-6

Enviado: 23/09/2011

Reenviado: $23 / 11 / 2011$

Aceito: 09/02/2012 